\title{
Development of Wireless Sensor Networks for Underground Communication and Monitoring Systems (The Cases of Underground Mine Environments)
}

\author{
Mohammad Ali Moridi a, Mostafa Sharifzadeh ${ }^{\text {a }}$, Youhei Kawamura ${ }^{\text {b }}$, Jang Hyongdoo ${ }^{\text {a }}$ \\ a Department of Mining Engineering and Metallurgy Engineering, Western Australian School of Mines (WASM), \\ Curtin University, 6433, Australia \\ ${ }^{b}$ Graduate School of Engineering and Resource Science Department of Materials-process Engineering and \\ Applied Chemistry Environment, Akita University, 010-8502, Japan
}

\begin{abstract}
The challenges of maintaining safe workplaces and improving operations and services in underground mines are unique. These have largely been mitigated by implementing new technology of wireless sensor networks (WSNs) in the last few years. Establishment and development of a reliable monitoring and communication network through such hostile environments are still major concerns. In this study, a more comprehensive monitoring and communication system for underground mine environments using ZigBee network are developed. To this regard, experiments with real systems and prototypes are applied. The controllable and uncontrollable parameters of both underground environment and network for the establishment of ZigBee network are also assessed. Then, a practical method to design a model of an underground mine monitoring and communication system is proposed. This model was verified by testing system functions and applications for example, temperature, humidity and illumination readings, text messaging, and controlling ventilation fans throughout an underground mine in Western Australia. The monitoring and communication systems operated successfully and it demonstrated the reliable outcomes of their function and application for underground mines.
\end{abstract}

Key words: underground mine, monitoring and communication system, wireless sensor network, ZigBee network 


\section{Introduction}

The development of a wireless sensor network (WSN) model is hugely beneficial for the practical design of underground mine monitoring and communication systems. This is mostly owing to the large variety of networking variables, the rapid technological advancement of sensor nodes, and considerable changes in environmental parameters from one mine site to another one.

Thus, a recognition of entire variables is a key component for the evaluation of the reliability of the WSNs' functions and applications in an underground mine. Ben Maissa, Kordon, Mouline, and Thierry-Mieg (2013) emphasised the necessity of investing in WSNs' performance, based on model analysis and validation, before handling more critical functions. Stanley-Marbell et al. (2008) observed the impact of the WSNs' operation taking into account the variables of the hardware, software and physical limitations. They focused on the importance of recognising the uncontrollable parameters of the environment and runtime parameters in order to develop a more realistic model and evaluate the performance of WSNs under a system model. This work attempted to provide models of WSNs which predicted system properties and challenges associated with cost and time effectiveness on a real project. This study will demonstrate a practical system design for establishing a reliable WSN for required underground functions and applications in underground environments. In particular, it shows that how the confirmation and calibration of a WSN model using ZigBee network is developed based on the field investigations. The controllable and uncontrollable parameters of both the network and underground environments are considered so as to establish and further develop wireless monitoring and communication systems in underground openings.

The procedure of establishment and development of a WSN in an underground mine is illustrated in Figure 1. The specification of the underground network should be first drawn 
up in order to design a monitoring and communication system which could be utilised for communication, environment monitoring, tracking or any combination of these. Consequently, the determination of required stationary or/and mobile sensors contributes to an evaluation of the controllable and uncontrollable parameters through the network as well as underground environment. Then, a model of the system is designed. This is experimentally analysed for the verification of the network setup and the reliability of the functions and applications. In the event of satisfactory results, the generalisation of the model is very likely to establish a reliable monitoring and communication system between a control room and levels of an underground mine.

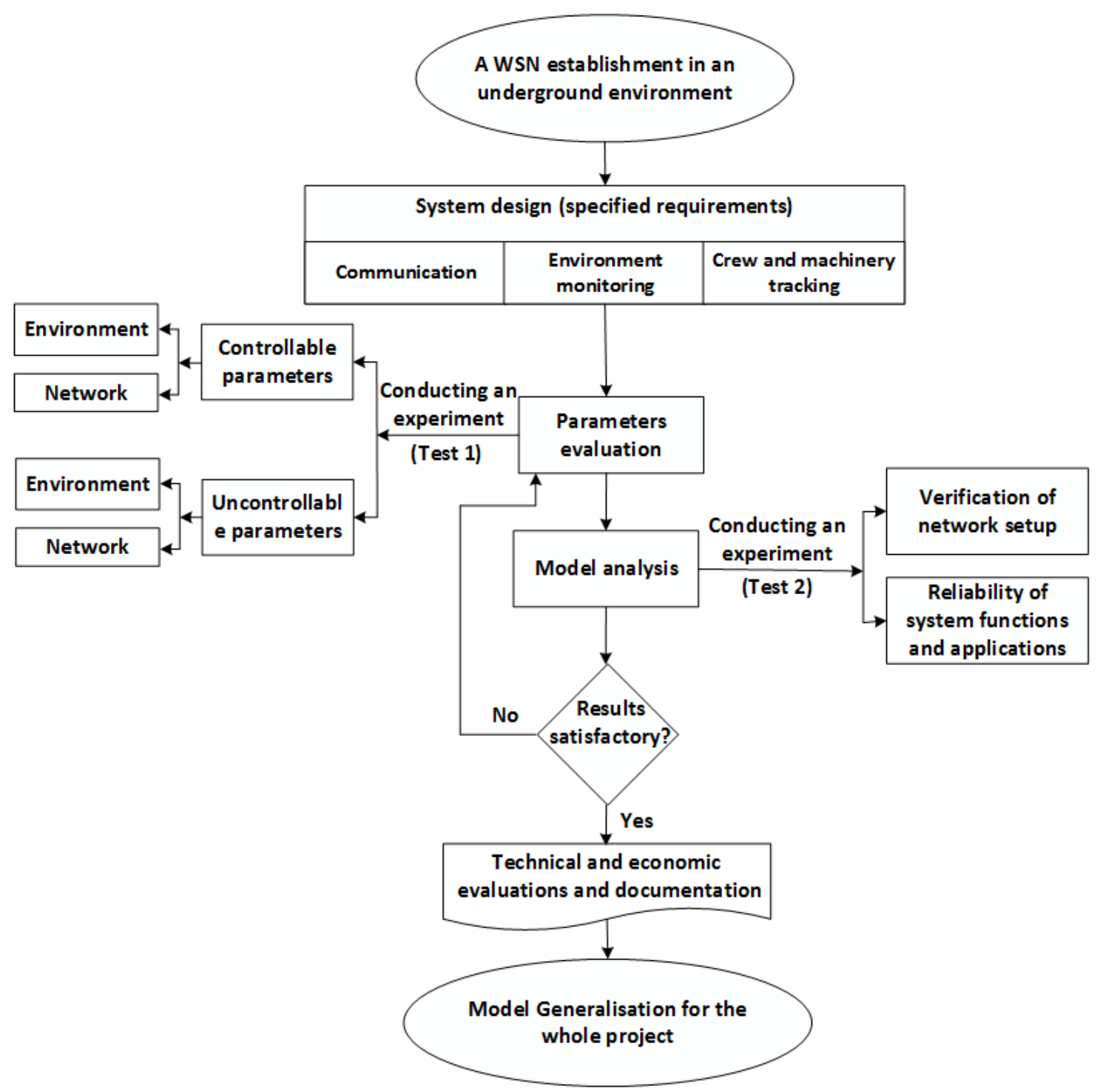

Figure 1. Procedure of establishment and development of a WSN in underground mines 
The remainder of this paper is organised as follows. The effective parameters for the establishment of a ZigBee network in an underground mine is first evaluated. Then, a system design and model is developed based on the classification of results from an experiment undertaken at an underground mine in Western Australia. Following that, another experiment is conducted to physically verify the reliability of the proposed ZigBee network model in this particular mine. This is performed by testing the system's functions and applications including messages texting and controlling ventilation fan operations as a model. Finally, the results of experiments are discussed with a subsequent of the directional line of sight and non-line of sight and the position of the nodes.

\section{ZigBee Network Modelling in Underground Mines}

In order to implement an underground monitoring and communication system, building a model is necessary for the assessment of technical and economic evaluations. This is based on determining required functions and applications, and the recognition of the variables of network metrics and environmental variables in the specified environment.

\subsection{Parameters evaluation}

Moridi, Kawamura, Sharifzadeh, Chanda, and Jang (2014) selected and simulated ZigBee networks for monitoring and communication in underground environments and concluded that recognising and assessing the effective parameters is crucial in a network design. Zarei, Uromeihy, and Sharifzadeh (2013) posited a method for assessing the principal parameters of tunnels water inflow. Accordingly, the controllable and uncontrollable parameters of a ZigBee network and the surrounding environment are illustrated in Figure 2. 


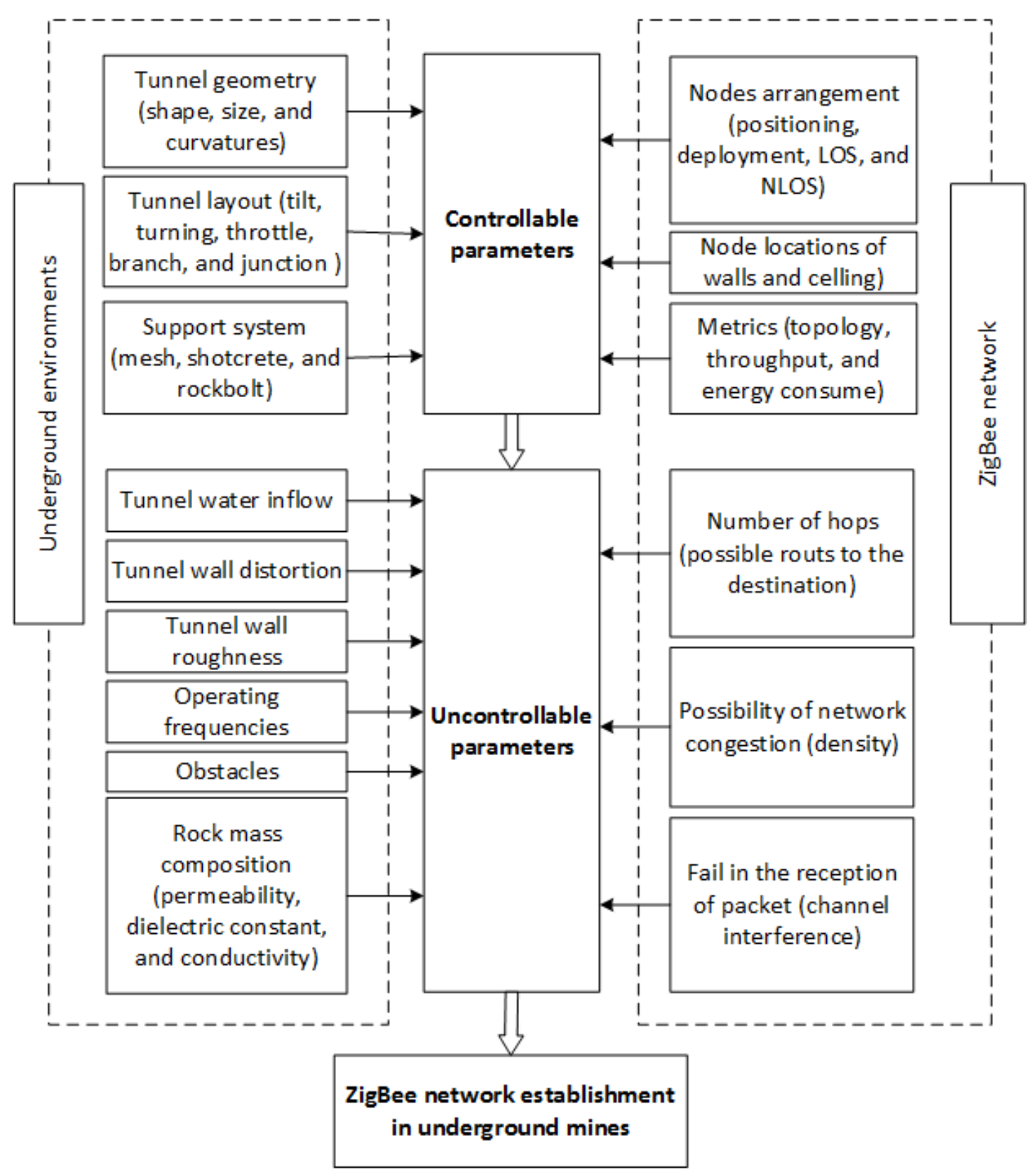

Figure 2. Principal steps for assessing a ZigBee network establishment in underground

mines

There are a considerable number of uncontrollable parameters which contribute to the complexities of any model simulating the real world. Some parameters of a ZigBee network (Figure 1) such as the arrangement and localization of nodes and the network metrics are adjustable for better data telemetry in underground mines. The uncontrollable parameters are the number of hops, network congestion and infrequent failures in the reception of data packets. It might be possible to render these parameters controllable within confined spaces. 
There are also environmental variables of tunnels that are uncontrollable in ZigBee network design as opposed to the known or controllable parameters of tunnel geometry, layout and employed system support. Such uncontrollable parameters include the rate of water inflow fluctuation, the degree of wall surface distortion and roughness, the radio frequency interferences of operating and communication systems, obstacles like dump trucks, boggers, and air compressors, as well as the variation rate of permeability, dielectric constants, and conductivity in the surrounding rock mass along openings.

Therefore, a ZigBee network can efficiently be established after determining the underground effective parameters that influence ZigBee communication signals, and finding the maximum reliable communication distance between nodes in different underground openings with all variables considered. Thus, quantifying all of the above parameters is a prerequisite for the design of a reliable ZigBee network for underground openings.

\subsection{System design and modelling}

In order to design an underground monitoring and communication system using a ZigBee network, the system design criteria must be selected based on the results of the entire network behaviour experiment at that particular level of the underground mine. The conduct of such an experiment is crucial because of varying effects of underground environmental features and ongoing mining on the complexity of radio communication distances.

Input, process and output for an underground monitoring and communication system design and model are illustrated in Figure 3. Access to basic information including ZigBee nodes technology, desired applications (such as environmental monitoring, ventilation management, and type of communication) as well as mine site details such as geological and levels maps are mandatory for system design and modelling. Normally, system modelling is utilised to verify system design, (Robinson, 2012). Therefore, a pilot experiment must be conducted to prove the principles governing the system design and 
modelling of an underground ZigBee network. The output of the model will lead to a reliable indicative outcome for required functions and applications.

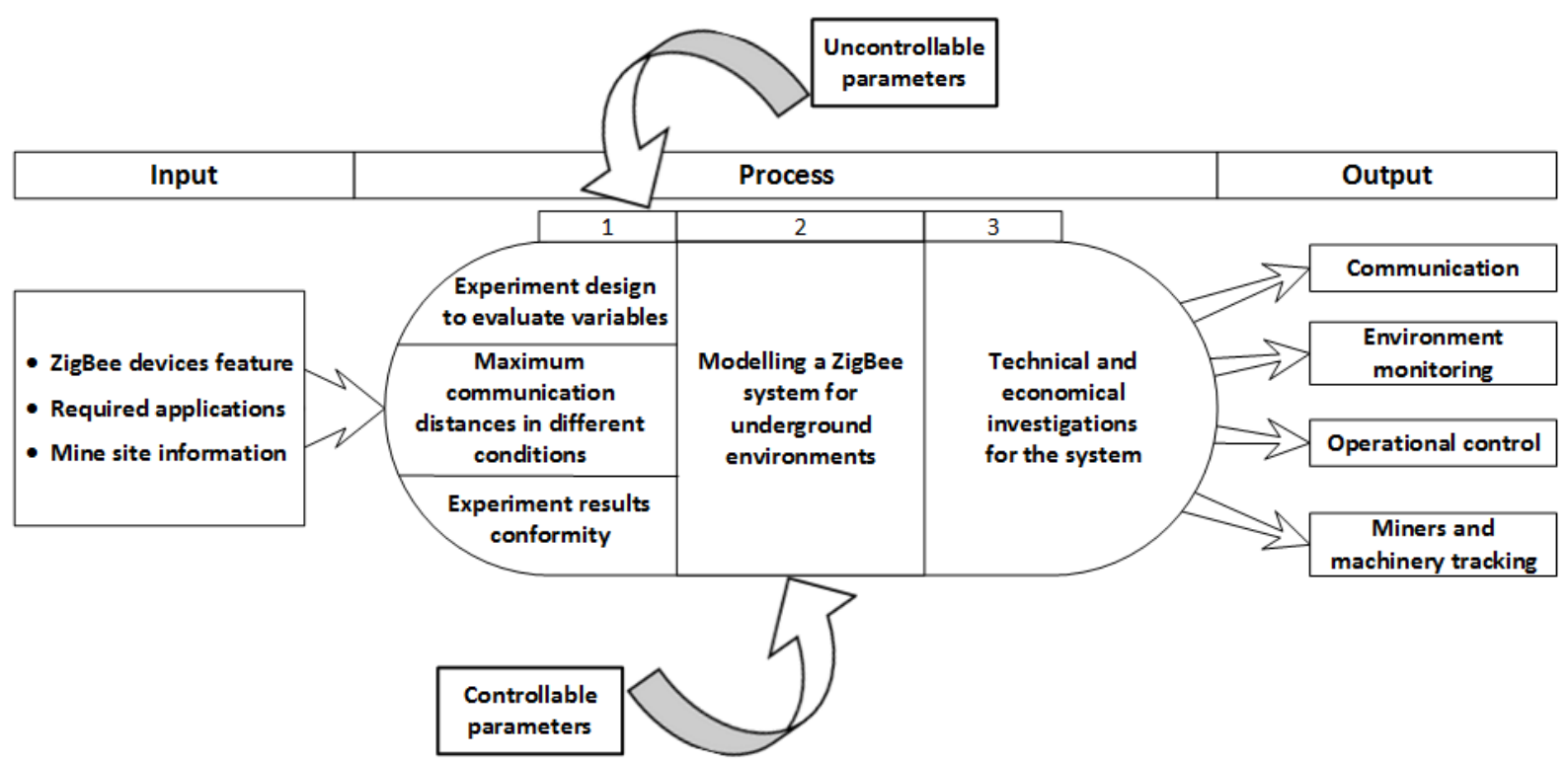

Figure 3. Diagram of system design and model of an underground mine monitoring and communication system

\subsection{Model generalisation}

The aim of generalising the ZigBee model in underground mines is to be able to implement a systematic feasibility study of technical and economic evaluations, based on the system design and modelled results. This procedure is illustrated in Figure 1. Investigations of the ZigBee network model applied in underground spaces can be empirically verified. Numerous running and adjusting ZigBee functions and applications may be required before an adequately reliable system design is achieved. Results documentation of the process would undoubtedly be valuable to justify any investment which might convince mine managers of the benefits of such an innovative system.

\section{Case study I - An Underground Environment Experiment for System Design}

An experiment is designed to investigate the reliability of a wireless underground mine monitoring and communication system. To this end, the maximum distance of radio 
communication is evaluated in different conditions of underground environments and ZigBee nodes arrangement and location. After analysis of the measurements and classification of results, the system design for a reliable ZigBee network can be developed for underground application.

An experiment was conducted in Tunnel 11 at level 9415 of a nickel underground mine in Western Australia at a depth of approximately 1000 metres. A layout of the test location in this level is illustrated in Figure 4. The test lines in the experiment were conducted in two accesses (415 and 390) of this tunnel. Access 415 is a straight opening whereas access 390 is a curved opening.

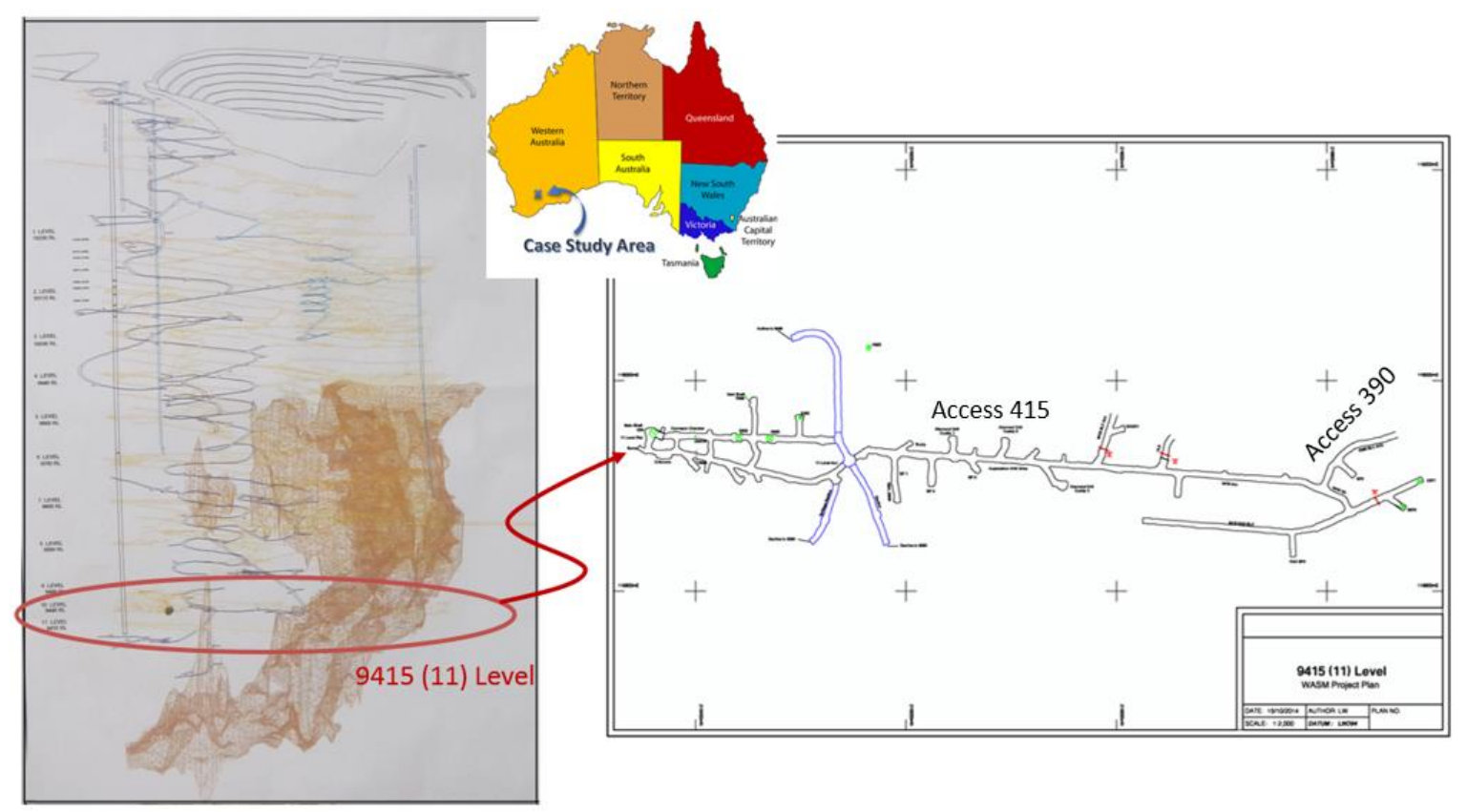

Figure 4. Layout of test location in tunnel 11at level $9415 \mathrm{~m}$

\subsection{Experiment preparation}

In this experiment, IEEE 802.15.4 standard and ZigBee evaluation development kit (EDK) based on TOCOS engine were employed. One ZigBee Coordinator (TWE-EK-002-LCD-SIP), two ZigBee routers (TWE-EK-002-NLC-SIP), one laptop with software development environment (SDK), the TOCOS-TagViewer, two tripods, and one measurement tape were used. The employed ZigBee router (node) uses a default maximum transmitting power of 3 
$\mathrm{dBm}$ in the condition of communication (Moridi et al., 2018). It also enables measurement of signal strength (LQI) and sensing of environment attributes such as temperature, humidity and luminance. Information recorded by TOCOS-TagViewer is presented in Table 1.

Table 1. Recorded information by TOCOS-TagViewer

\begin{tabular}{|c|c|c|c|c|c|c|c|c|c|}
\hline \multicolumn{10}{|c|}{ MAC address of Transmitted side: $001 \mathrm{BC} 501$ : 20B0075C } \\
\hline 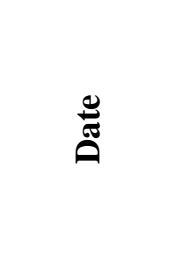 & $\stackrel{g}{g}$ & $\bar{\partial}$ & 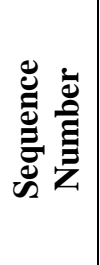 & 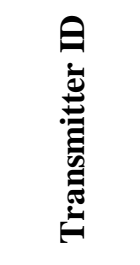 & 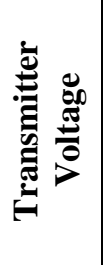 & 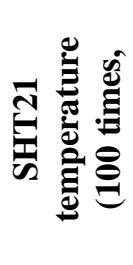 & 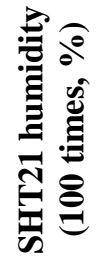 & 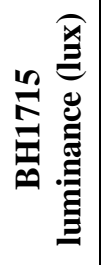 & 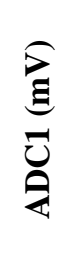 \\
\hline $11 / 11 / 2014$ & 2:05:01 PM & 156 & 15 & 0b0075c & 3070 & 2917 & 6428 & 0 & 742 \\
\hline $11 / 11 / 2014$ & 2:05:06 PM & 153 & 16 & 0b0075c & 3070 & 2917 & 6423 & 0 & 741 \\
\hline $11 / 11 / 2014$ & 2:05:11 PM & 162 & 17 & 0b0075c & 3070 & 2917 & 6423 & 0 & 740 \\
\hline
\end{tabular}

The underground attenuation of ZigBee nodes was considered in this experiment. The measurement of WSN's communication distance is attained based on the acceptable radio signal strength of a received data packet in terms of the Link Quality Indication (LQI) value. Ha, Eun, and Byun (2013) held that although RSSI (received signal strength indicator) provides a traditional metric for radio transceivers, LQI is an effective metric which has become more common in the latest ZigBee transceivers such as Chipcon's CC2420. Underground mining water inflow, mining equipment, and some physical properties of tunnels such as curvature, support system have an extreme impact on RSSI attenuation due to reflection and scattering (Benkic et al., 2008). Therefore, LQI values are more reliable for link quality estimation and have a higher correlation with the distance between ZigBee nodes compared with RSSI values and this is selected as a distance estimator in this work. LQI is an integer in the range $0-255$ where 255 represents the strongest signal. The 
relationship between the LQI value and the detected power, $\mathrm{P}$, in $\mathrm{dBm}$ for the ZigBee node in this experiment (JN5148), is approximately given by equation (1).

$\mathrm{P}=(7 * \mathrm{LQI}-1970) / 20$

Equation (1)

Equation (1) is valid for $0<\mathrm{LQI}<255$. Reliable LQI for certain data transmission between ZigBee nodes is practically assumed to be greater than 50 or over $-80 \mathrm{dBm}$ of RSSI values (Moridi et al., 2014). Therefore, the recorded information in this experiment would be analysed on this basis.

The experiment investigated the attenuation tendency of radio wave intensity. This includes the estimation method of the maximum distance between ZigBee nodes in the different underground conditions based on appropriate LQI for being cognisant of identifiable variables. For this purpose, the test lines were designed where the distance between the two ZigBee nodes increases continuously at certain intervals until the LQI drops lower than the specified limit.

The procedure for LQI measurements in Tunnel 11 of the nickel mine are illustrated in Figure 5. In this procedure, the coordinator was connected to the laptop (PC) for recording data while the ZigBee nodes were mounted on tripods to gauge signal strength. For consistency of the results, the measurements were repeated at least 5 times for each interval. 


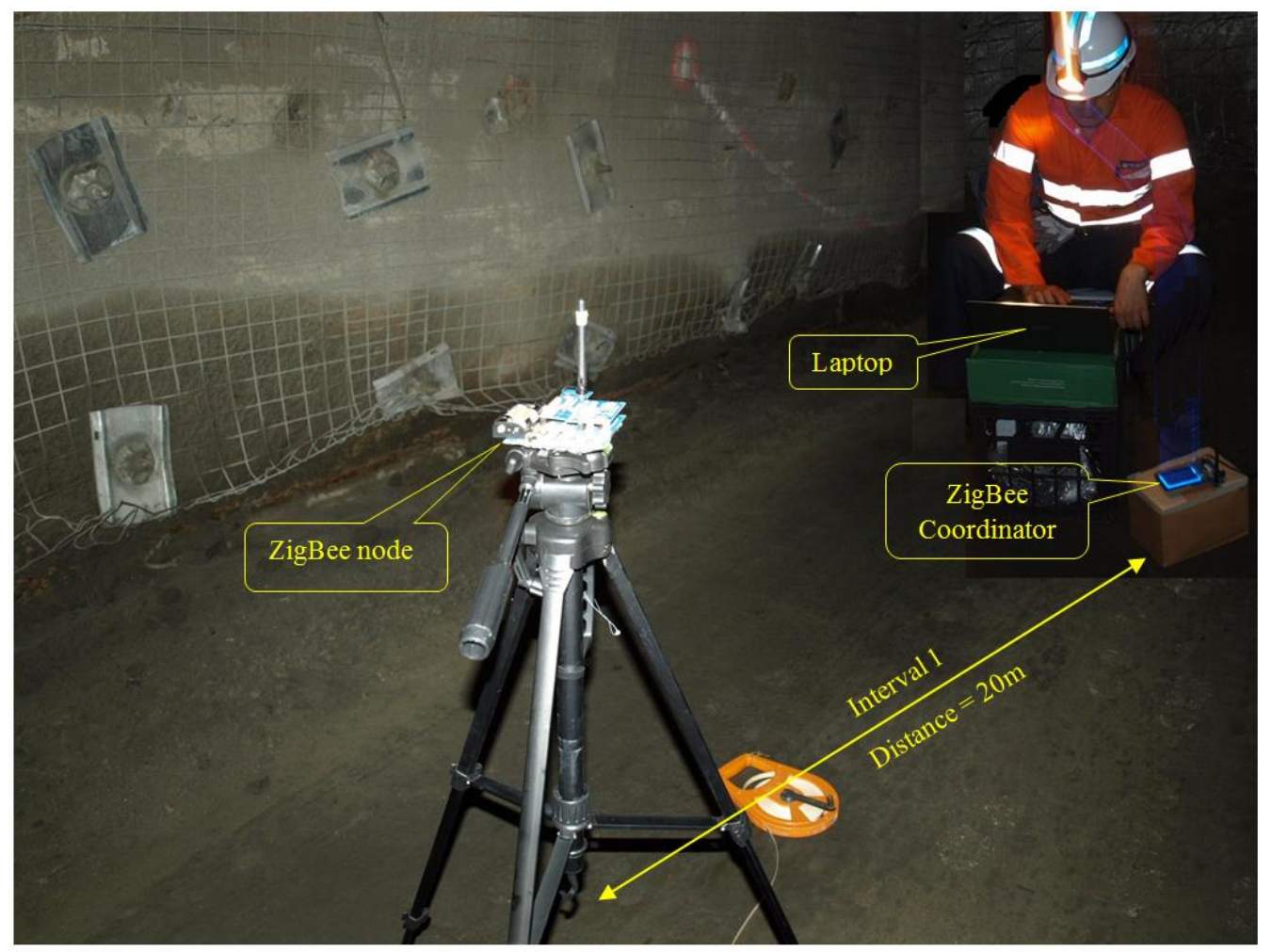

Figure 5. Procedure of LQI measurements along the tunnel

\subsection{Experiment measurements and results}

The experiment measurements were carried out in five tests lines described below in different conditions at level 11.

A. Test 1: In this test, the ZigBee coordinator was located in the middle of the tunnel at level 11/ 415 access. The ZigBee node was placed on a tripod at a $1.5 \mathrm{~m}$ height to minimise the signal propagation because of signal scattering caused by floor surface and appropriately located in the middle of the tunnel at $20 \mathrm{~m}$ intervals. The test line was then placed in the middle of tunnel being isolated from the side effects of the walls and floor. The layout of the tunnel and the position of ZigBee node at each interval are illustrated in Figure 6. The fluctuation of the signal strength based on the LQI versus distance increase is also illustrated in Figure 7. 


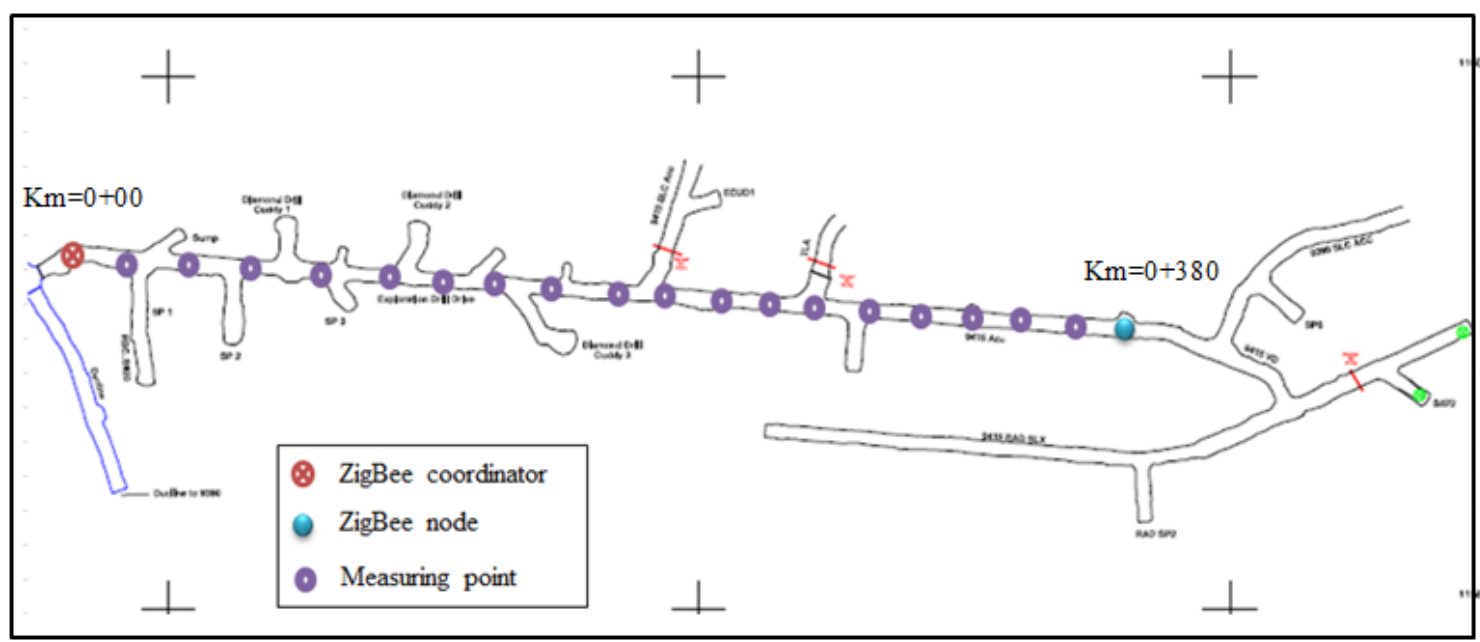

Figure 6. Position of the ZigBee node and coordinator at the specified intervals in Test 1

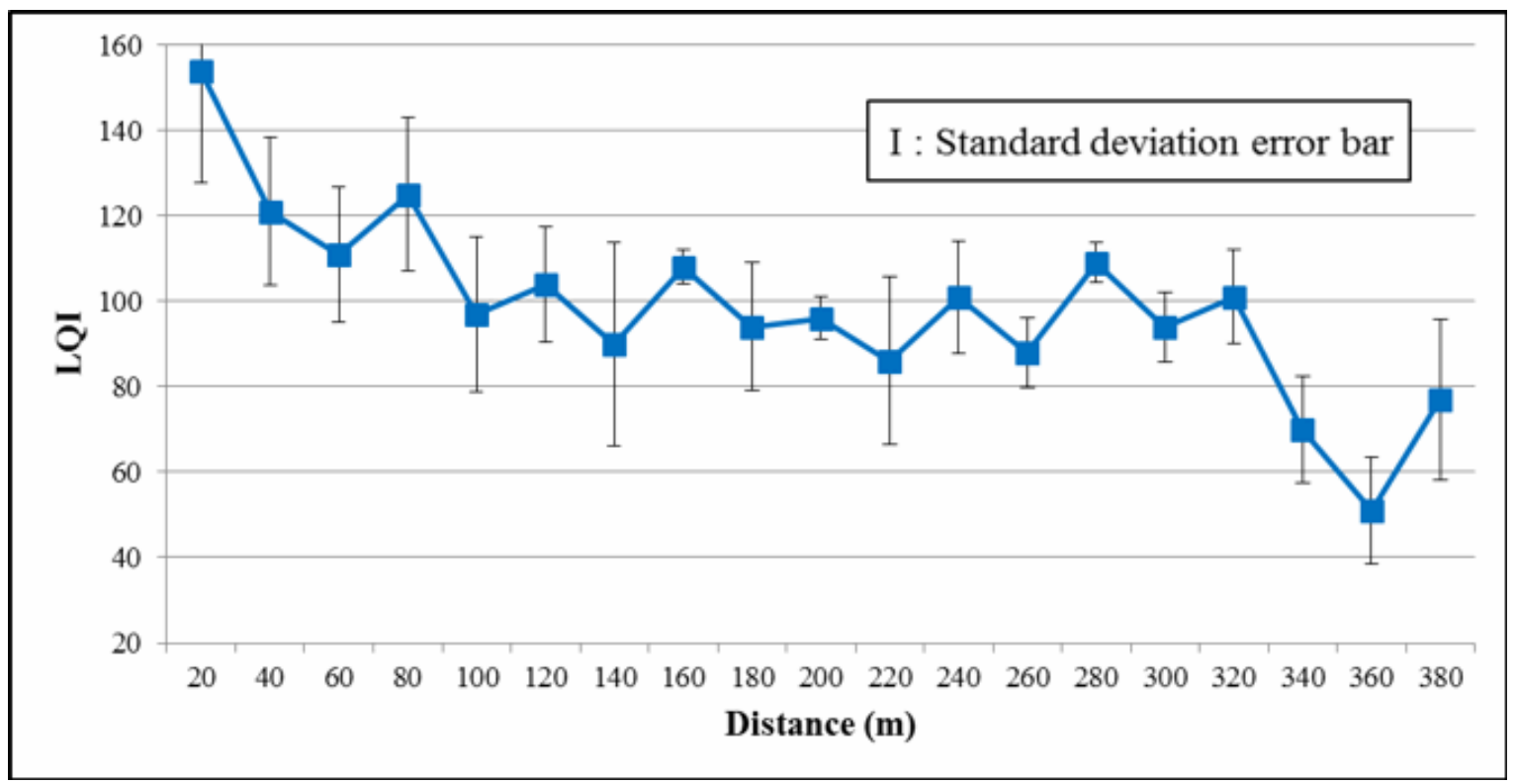

Figure 7. Signal strength based on the LQI versus distance increase in Test 1

B. Test 2: The test was performed at the level 11/ 415 access and a ZigBee node was placed on the tripod located close to the tunnel wall at $30 \mathrm{~m}$ intervals. The coordinator was also close to the wall. The test line was straight and located nearby the tunnel wall. Figure 8 shows the position of the ZigBee node with increasing distance remote from the coordinator at the specified interval. The signal strength based on the LQI versus distance increased is also illustrated in Figure 9. 


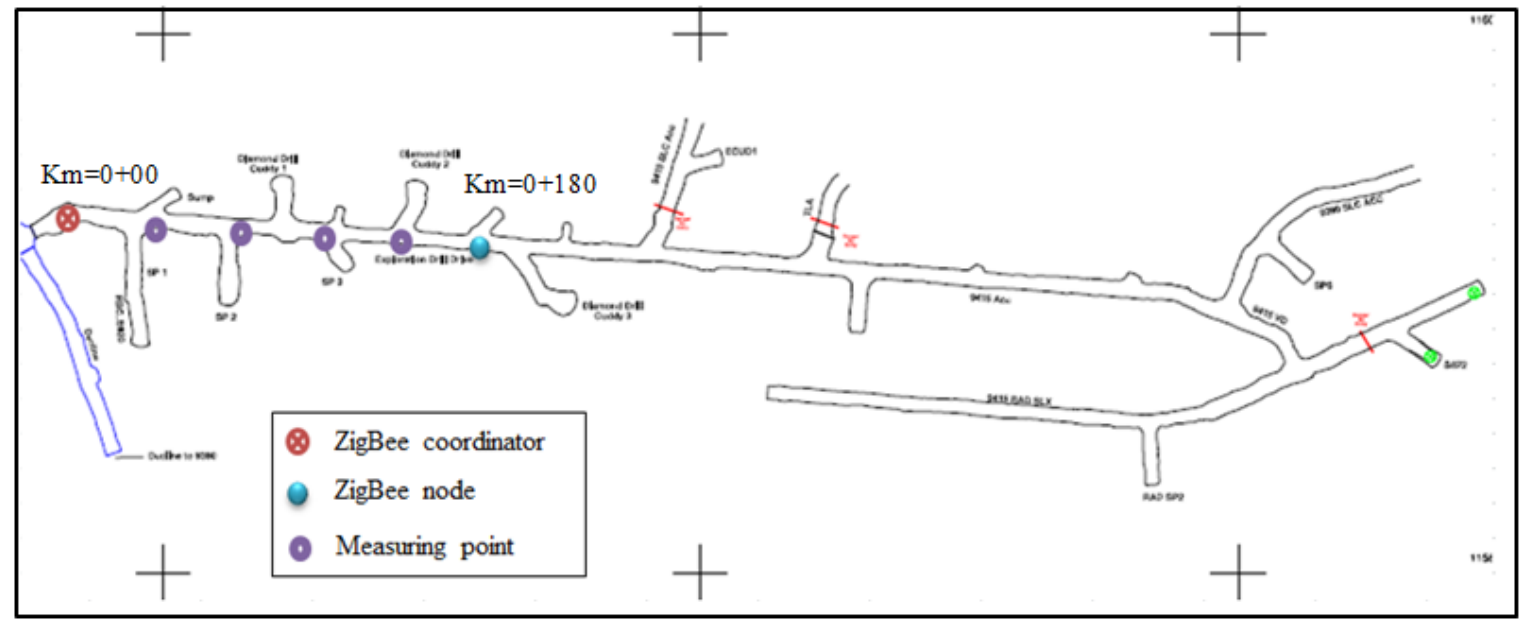

Figure 8. Position of the ZigBee node and coordinator at the specified intervals in Test 2

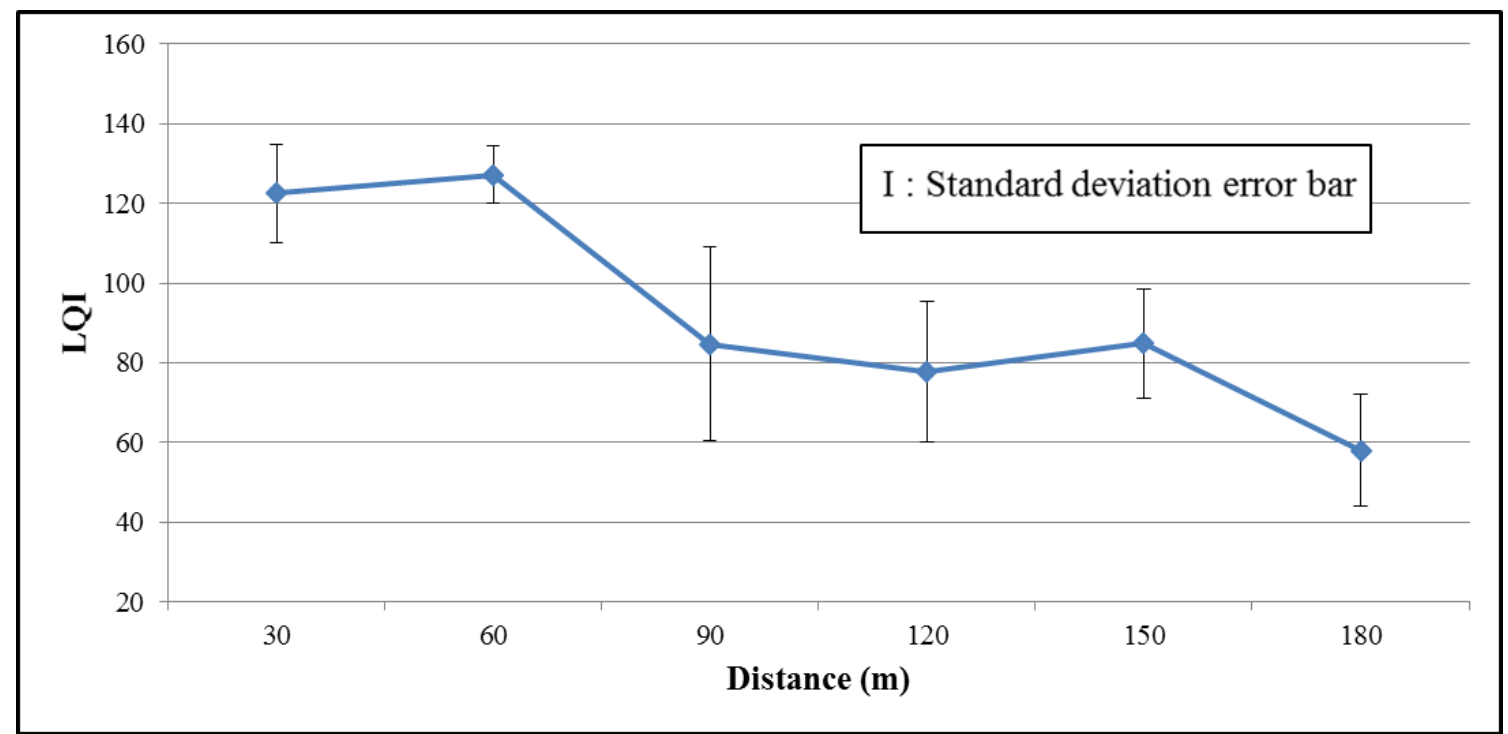

Figure 9. Signal strength based on the LQI versus distance increase in Test 2

C. Test 3: The test was performed at the level 11/ 415 access. The ZigBee node was placed on the floor located in the middle of the tunnel at $20 \mathrm{~m}$ intervals. The test line was situated in the middle of the tunnel located on the floor without tripods. Figure 10 shows the position of ZigBee node which is at increasing distance remote from the coordinator at the specified interval. The signal strength based on the LQI versus distance increase is illustrated in Figure 11. 


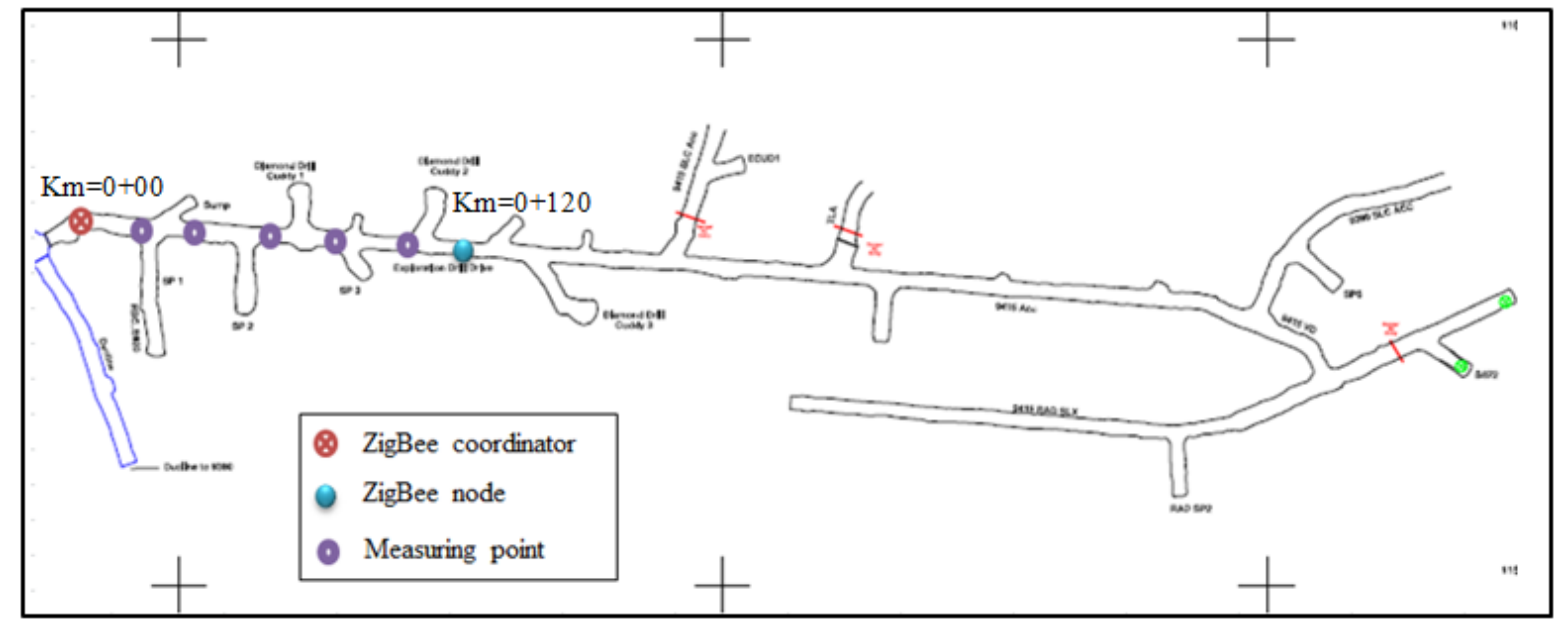

Figure 10. Position of the ZigBee node and coordinator at the specified intervals in Test 3

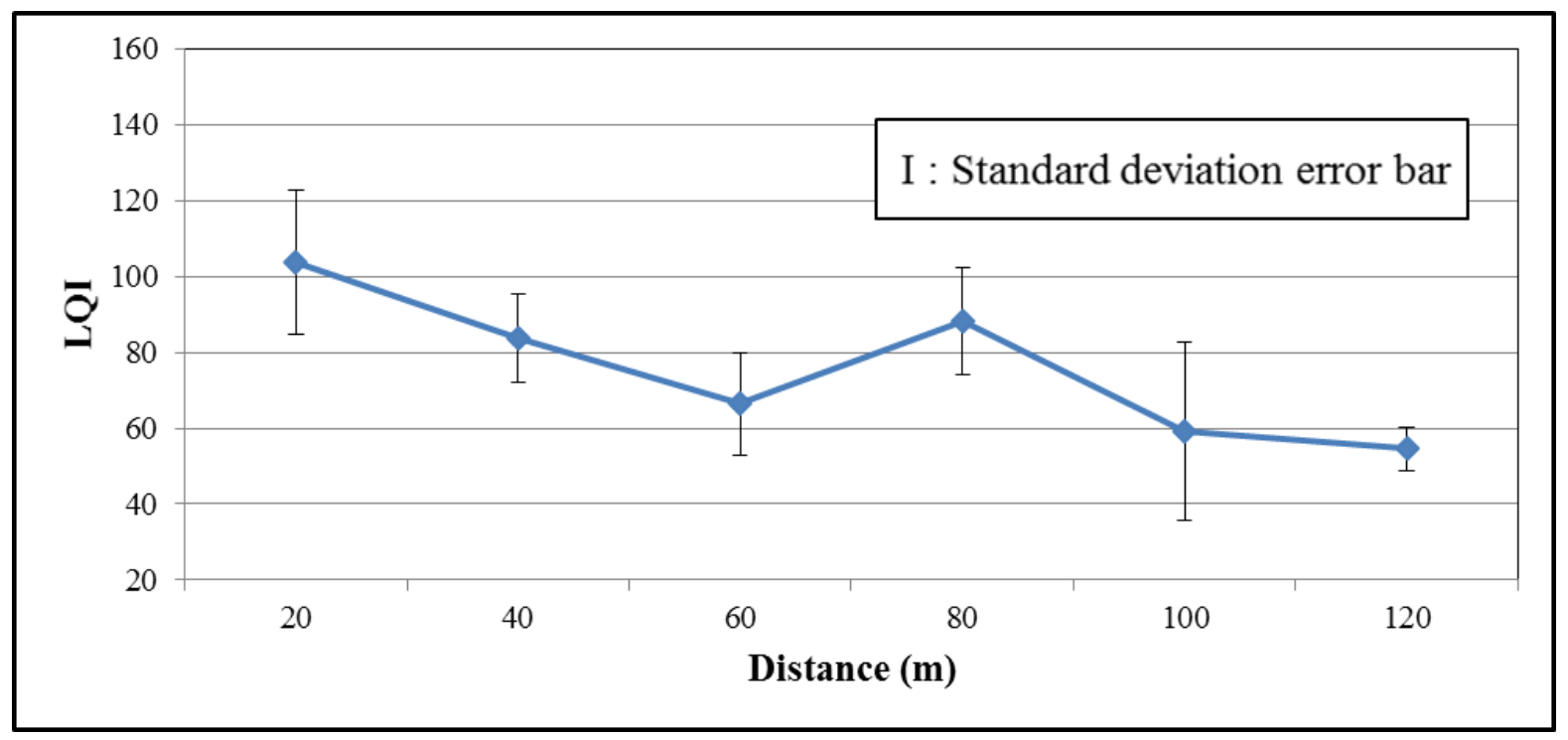

Figure 11. Signal strength based on the LQI versus distance increase in Test 3

D. Test 4: The test was performed at the level 11/ 415 access. The ZigBee node was placed on the tripod located close to the tunnel wall at $20 \mathrm{~m}$ intervals. The coordinator was on the opposite side to the node position (non-line of sight). Figure 12 shows the position of ZigBee node with increasing distance remote from the coordinator at the specified interval. The signal strength based on the LQI versus distance increase is illustrated in Figure 13. 


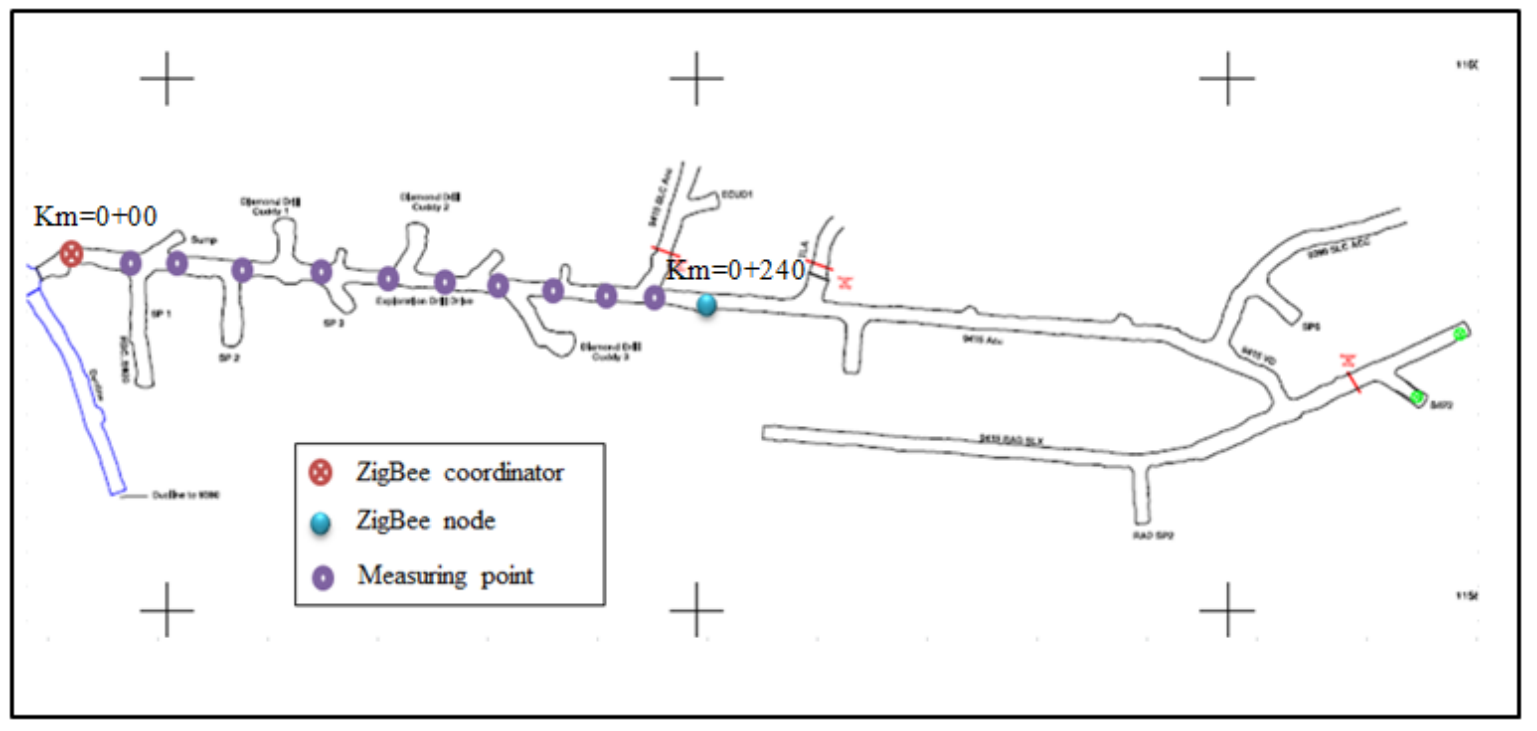

Figure 12. Position of the ZigBee node and coordinator at the specified intervals in Test 4

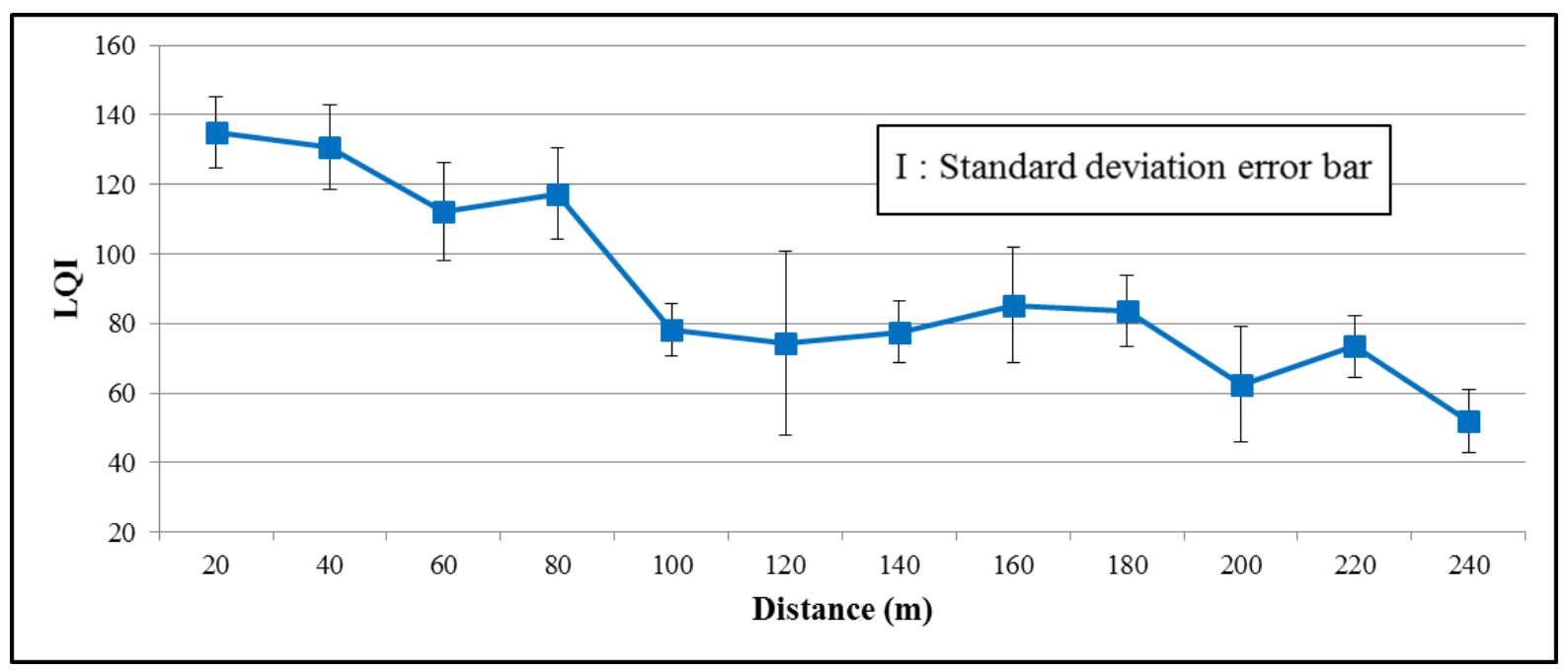

Figure 13. Signal strength based on the LQI versus distance increase in Test 4

E. Test 5: The test was performed in a curvature at the level 11/390 access. The ZigBee node was placed on the tripod located in the middle of the tunnel at $20 \mathrm{~m}$ intervals (non-line of sight) ad at a high dip angle. The test line was located in the middle and far from the walls and floor of the tunnel. Figure 14 shows the position of ZigBee node with increasing distance remote from the coordinator at the specified interval. The signal strength based on the LQI versus distance increase is illustrated in Figure 15. 


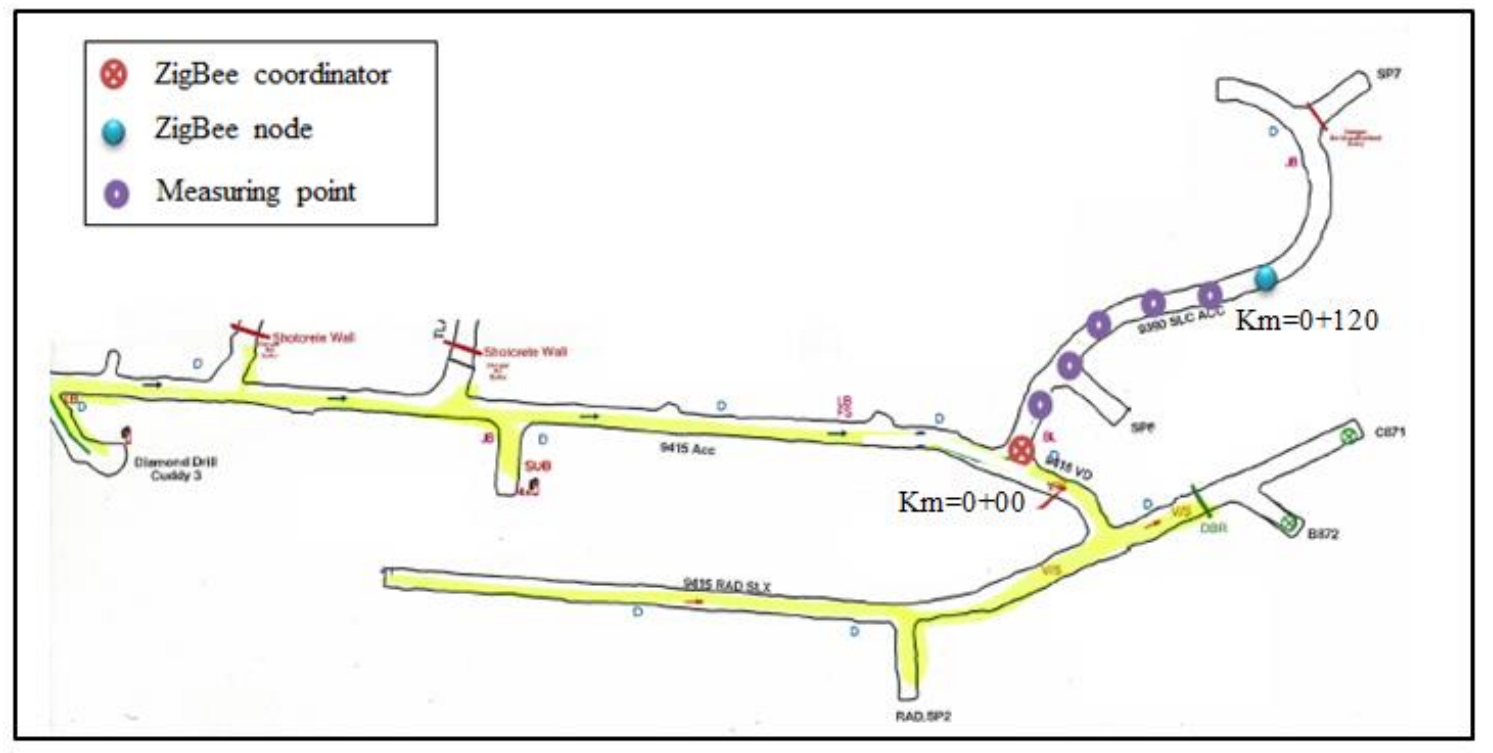

Figure 14. Position of the ZigBee node and coordinator at the specified intervals in Test 5

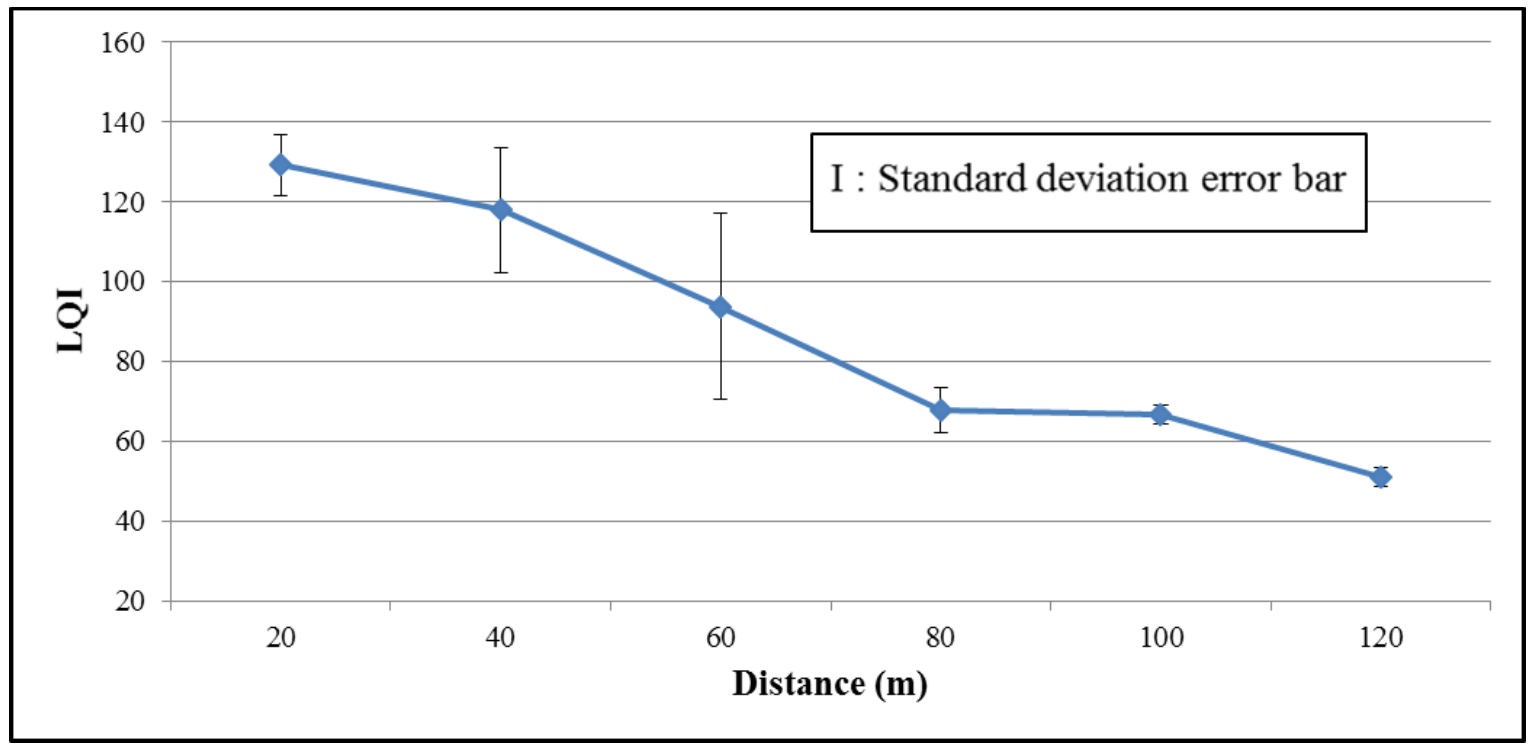

Figure 15. Signal strength based on the LQI versus distance increase in Test 5

\subsection{Discussion on the test results of case study I}

Tests results are briefly summarised in Table 2 considering the directional line of sight and non-line of sight and the position of the nodes. The position of nodes in the tests represents the location of the test line from tunnel walls and floor to determine the factors affecting the maximum communication distance. As seen in Table 2, the parameters such as the wall roughness and distortion, the floor and the curvature of the tunnel and the arrangement of nodes could substantially impact the signal attenuation and reduced communication distance between ZigBee nodes. That is why an experiment is required to design a wireless monitoring and 
communication system in every underground opening considering the specific nature and circumstance of each.

Table 2. Experiment results - Summary of the maximum communication distance between ZigBee nodes under different conditions

\begin{tabular}{|c|c|c|c|}
\hline \multicolumn{2}{|c|}{ Descriptions } & \multirow{2}{*}{ Communication distance $(\mathrm{m})$} & \multirow{2}{*}{$\begin{array}{l}- \text { Tunnel plan view, } \\
-\bullet \text { Test line }\end{array}$} \\
\hline Test line & Node positions & & \\
\hline Straight line & in the tunnel axis & 380 & \\
\hline Straight line & on the tunnel wall & 180 & \\
\hline $\begin{array}{c}\text { Diagonal straight } \\
\text { line }\end{array}$ & $\begin{array}{l}\text { on the opposite tunnel } \\
\text { walls }\end{array}$ & 240 & \\
\hline Straight line & on the floor of tunnel & 120 & L- - - - \\
\hline Curved line & $\begin{array}{l}\text { in the middle of } \\
\text { curved tunnel }\end{array}$ & 120 & \\
\hline
\end{tabular}

The results are analysed and classified to develop a more rigorous system design of a ZigBee network taking into account relevant factors in the underground openings. The effect of tunnel curvature on communication distance is indicated in Table 3. Communication distance leads to a dramatic drop from $380 \mathrm{~m}$ in a line of sight of radio propagation compared with $120 \mathrm{~m}$ in a non-line of sight under the similar conditions with respect to support system, test line position from the walls and the floor and the level of the ZigBee nodes. However, tunnel water inflow caused greater attenuation in the line of sight test.

Table 3. Classification of results based on the passageway effect

\begin{tabular}{|c|c|c|c|c|c|c|c|}
\hline $\begin{array}{l}\text { Test line } \\
\text { view }\end{array}$ & $\begin{array}{c}\text { Radio } \\
\text { propagation } \\
\text { regions }\end{array}$ & $\begin{array}{l}\text { Tunnel } \\
\text { layout }\end{array}$ & $\begin{array}{l}\text { Support } \\
\text { system }\end{array}$ & $\begin{array}{c}\text { Test } \\
\text { line } \\
\text { position }\end{array}$ & $\begin{array}{c}\text { ZigBee } \\
\text { node level }\end{array}$ & $\begin{array}{c}\text { Water } \\
\text { conditions }\end{array}$ & $\begin{array}{c}\text { ZigBee } \\
\text { communication } \\
\text { distance }(\mathbf{m})\end{array}$ \\
\hline L- & $\begin{array}{l}\text { line of sight } \\
\text { (LOS) }\end{array}$ & straight & $\begin{array}{l}\text { mesh } \\
\text { shotcrete } \\
\text { rock bolt }\end{array}$ & $\begin{array}{l}\text { in the } \\
\text { tunnel } \\
\text { axis }\end{array}$ & $\begin{array}{l}\text { On a tripod } \\
\text { with } 1.5 \mathrm{~m} \\
\text { height }\end{array}$ & $\begin{array}{l}\text { water } \\
\text { inflow } \\
\text { through a } \\
\text { ditch }\end{array}$ & 380 \\
\hline & $\begin{array}{l}\text { non-line of } \\
\text { sight } \\
\text { (NLOS) }\end{array}$ & $\begin{array}{l}\text { curved and } \\
\text { inclined }\end{array}$ & $\begin{array}{c}\text { mesh } \\
\text { shotcrete } \\
\text { rock bolt }\end{array}$ & $\begin{array}{l}\text { in the } \\
\text { tunnel } \\
\text { axis }\end{array}$ & $\begin{array}{l}\text { On a tripod } \\
\text { with } 1.5 \mathrm{~m} \\
\text { height }\end{array}$ & dry & 120 \\
\hline
\end{tabular}


Classification of results based on the tunnel walls effect is indicated in Table 4. The communication distance between two ZigBee nodes in a straight tunnel falls rapidly from $380 \mathrm{~m}$ to $180 \mathrm{~m}$ where the test line changes the location from the middle of the tunnel to the nearby walls. This occurred when the tests were performed where there were similar conditions of tunnel layout, support system, ZigBee node height, and water inflow through a ditch.

Table 4. Classification of results based on the tunnel walls effect

\begin{tabular}{|c|c|c|c|c|c|c|}
\hline Test line view & $\begin{array}{l}\text { Test line } \\
\text { position }\end{array}$ & $\begin{array}{l}\text { Tunnel } \\
\text { layout }\end{array}$ & $\begin{array}{l}\text { Support } \\
\text { system }\end{array}$ & $\begin{array}{c}\text { ZigBee } \\
\text { node level }\end{array}$ & $\begin{array}{c}\text { Water } \\
\text { conditions }\end{array}$ & $\begin{array}{c}\text { ZigBee } \\
\text { communication } \\
\text { distance }(\mathbf{m})\end{array}$ \\
\hline$\overline{L-1----L}$ & $\begin{array}{l}\text { in the } \\
\text { tunnel axis }\end{array}$ & $\begin{array}{l}\text { straight } \\
\text { tunnel }\end{array}$ & $\begin{array}{l}\text { mesh } \\
\text { shotcrete } \\
\text { rock bolt }\end{array}$ & $\begin{array}{c}\text { On a tripod } \\
\text { with } 1.5 \mathrm{~m} \\
\text { height }\end{array}$ & $\begin{array}{l}\text { water inflow } \\
\text { through a } \\
\text { ditch }\end{array}$ & 380 \\
\hline$\underline{L}$ & $\begin{array}{l}\text { on the } \\
\text { tunnel wall }\end{array}$ & $\begin{array}{c}\text { straight } \\
\text { tunnel }\end{array}$ & $\begin{array}{c}\text { mesh } \\
\text { shotcrete } \\
\text { rock bolt }\end{array}$ & $\begin{array}{l}\text { On a tripod } \\
\text { with } 1.5 \mathrm{~m} \\
\text { height }\end{array}$ & $\begin{array}{l}\text { water flow } \\
\text { through a } \\
\text { ditch }\end{array}$ & 180 \\
\hline
\end{tabular}

Results classified according to the evaluation of ZigBee nodes level- height effect is indicated in Table 5. ZigBee communication distance in this test reduced significantly from $380 \mathrm{~m}$ to $120 \mathrm{~m}$ mainly because of nodes placed in close proximity to the floor. In addition to the effect of floor unevenness which increases attenuation, the tunnel floor has an inclination of $0.3 \%$. For this reason, any line of sight tests where the distance between ZigBee nodes was greater than 100 m may have been considered as a non-line of sight test. This explains why the height of nodes placement becomes an important factor in the system design of a ZigBee network in underground excavations.

Table 5. Classification of results based on the ZigBee nodes level - height effect

\begin{tabular}{|c|c|c|c|c|c|c|}
\hline $\begin{array}{l}\text { Test line } \\
\text { view }\end{array}$ & $\begin{array}{c}\text { ZigBee } \\
\text { node level }\end{array}$ & $\begin{array}{l}\text { Test line } \\
\text { position }\end{array}$ & $\begin{array}{l}\text { Tunnel } \\
\text { layout }\end{array}$ & $\begin{array}{l}\text { Support } \\
\text { system }\end{array}$ & $\begin{array}{c}\text { Water } \\
\text { conditions }\end{array}$ & $\begin{array}{c}\text { ZigBee } \\
\text { communication } \\
\text { distance }(\mathbf{m})\end{array}$ \\
\hline 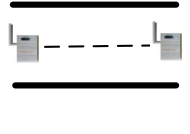 & $\begin{array}{l}\text { located on } \\
\text { tripod with } \\
1.5 \mathrm{~m} \text { height }\end{array}$ & $\begin{array}{l}\text { in the } \\
\text { tunnel axis }\end{array}$ & $\begin{array}{l}\text { straight } \\
\text { tunnel }\end{array}$ & $\begin{array}{c}\text { mesh } \\
\text { shotcrete } \\
\text { rock bolt }\end{array}$ & $\begin{array}{c}\text { water inflow } \\
\text { through a } \\
\text { ditch }\end{array}$ & 380 \\
\hline 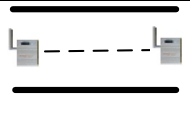 & $\begin{array}{l}\text { located on } \\
\text { the floor }\end{array}$ & $\begin{array}{l}\text { in the } \\
\text { tunnel axis }\end{array}$ & $\begin{array}{l}\text { straight } \\
\text { tunnel }\end{array}$ & $\begin{array}{c}\text { mesh } \\
\text { shotcrete } \\
\text { rock bolt }\end{array}$ & $\begin{array}{l}\text { water flow } \\
\text { through a } \\
\text { ditch }\end{array}$ & 120 \\
\hline
\end{tabular}


Results classified from the evaluation of ZigBee nodes arrangement is indicated in Table 6.

The communication distance increases from $180 \mathrm{~m}$ to $240 \mathrm{~m}$ provided that the test line changes from a straight to a diagonal one. This is derived from conducting tests under similar conditions and the same ZigBee node levels. Thus, the relative positioning of ZigBee nodes to each other could certainly be a definitive item in optimising an underground system design in terms of cost and energy efficiency.

Table 6 Classification of results based on the nodes arrangement effect

\begin{tabular}{|c|c|c|c|c|c|c|c|}
\hline $\begin{array}{l}\text { Test line } \\
\text { view }\end{array}$ & $\begin{array}{c}\text { Nodes } \\
\text { arrangement }\end{array}$ & $\begin{array}{l}\text { Tunnel } \\
\text { layout }\end{array}$ & $\begin{array}{l}\text { Test line } \\
\text { position }\end{array}$ & $\begin{array}{c}\text { ZigBee } \\
\text { node level }\end{array}$ & $\begin{array}{l}\text { Support } \\
\text { system }\end{array}$ & $\begin{array}{c}\text { Water } \\
\text { conditions }\end{array}$ & $\begin{array}{c}\text { ZigBee } \\
\text { communication } \\
\text { distance }(\mathbf{m}) \\
\end{array}$ \\
\hline$L_{-}$ & straight line & $\begin{array}{l}\text { straight } \\
\text { tunnel }\end{array}$ & $\begin{array}{l}\text { on the } \\
\text { tunnel wall }\end{array}$ & $\begin{array}{l}\text { On a tripod } \\
\text { with } 1.5 \mathrm{~m} \\
\text { height }\end{array}$ & $\begin{array}{c}\text { mesh } \\
\text { shotcrete } \\
\text { rock bolt }\end{array}$ & $\begin{array}{c}\text { water flow } \\
\text { through a } \\
\text { ditch }\end{array}$ & 180 \\
\hline & diagonal line & $\begin{array}{l}\text { straight } \\
\text { tunnel }\end{array}$ & $\begin{array}{l}\text { on the } \\
\text { opposite } \\
\text { tunnel } \\
\text { walls }\end{array}$ & $\begin{array}{l}\text { On a tripod } \\
\text { with } 1.5 \mathrm{~m} \\
\text { height }\end{array}$ & $\begin{array}{l}\text { mesh } \\
\text { shotcrete } \\
\text { rock bolt }\end{array}$ & $\begin{array}{c}\text { Water } \\
\text { inflow } \\
\text { through a } \\
\text { ditch }\end{array}$ & 240 \\
\hline
\end{tabular}

Therefore, it is confirmed that factors such as the passageway, the walls and the floor of a tunnel and the level and arrangement of ZigBee nodes have a major impact on radio wave attenuation and consequently on the distance of communication. On the basis of such experiment results, the design of a ZigBee network becomes more feasible taking into account a variety of parameters in an underground context.

\section{Case Study II - An Underground Environment Experiment for System Design Verification}

The purpose of this experiment is to verify the system design of a ZigBee network that has been based on the classified results obtained from communication distance experiments. This experiment also includes an investigation into the reliability of ZigBee functions and applications, specifically those involving the developed ZigBee nodes for bilateral underground mine communication (via message texting) as well as remote control of a 
ventilation system. Texting messages capability is only inspected in the experiments due to very low data rate $(250 \mathrm{kbps})$ for image, voice and video communication through ZigBee networks (Moridi et al., 2014). The ZigBee nodes applicable to this experiment are illustrated in Figure 16.

\subsection{Experiment preparation}

The system tested is composed entirely of different ZigBee nodes such as coordinator, routers and end nodes. These products were developed in collaboration with Tokyo Cosmos Electric Co., Ltd. The JN5148-EK010 kit (Jennic) stacks were used to create the ZigBee network. The wireless network is initially generated by the coordinator (gateway) which invites other nodes to join the network. A ZigBee coordinator (gateway) connected to the laptop (PC) used in the experiments is illustrated in Figure 16. The coordinator would normally be located in the surface office to allow users to monitor the underground mine, but was located in a refugee chamber room in the tunnel for this experiment. Sending and receiving messages and remote control of ventilation fans are also normally enabled by the surface coordinator.

Bilateral communication provides wireless connections between the coordinator and a radio station (end device) to send and receive messages and data readings taken and delivered by sensors. It is advantageous to locate the radio station including a ZigBee node and a tablet in a refugee chamber in the event of an emergency, particularly where there is a failure of primary communication systems such as telephones or leaky feeders. The extended capability of the ZigBee node connection to a cell phone is another communication support option between miners and refugee chambers or surface operators. 


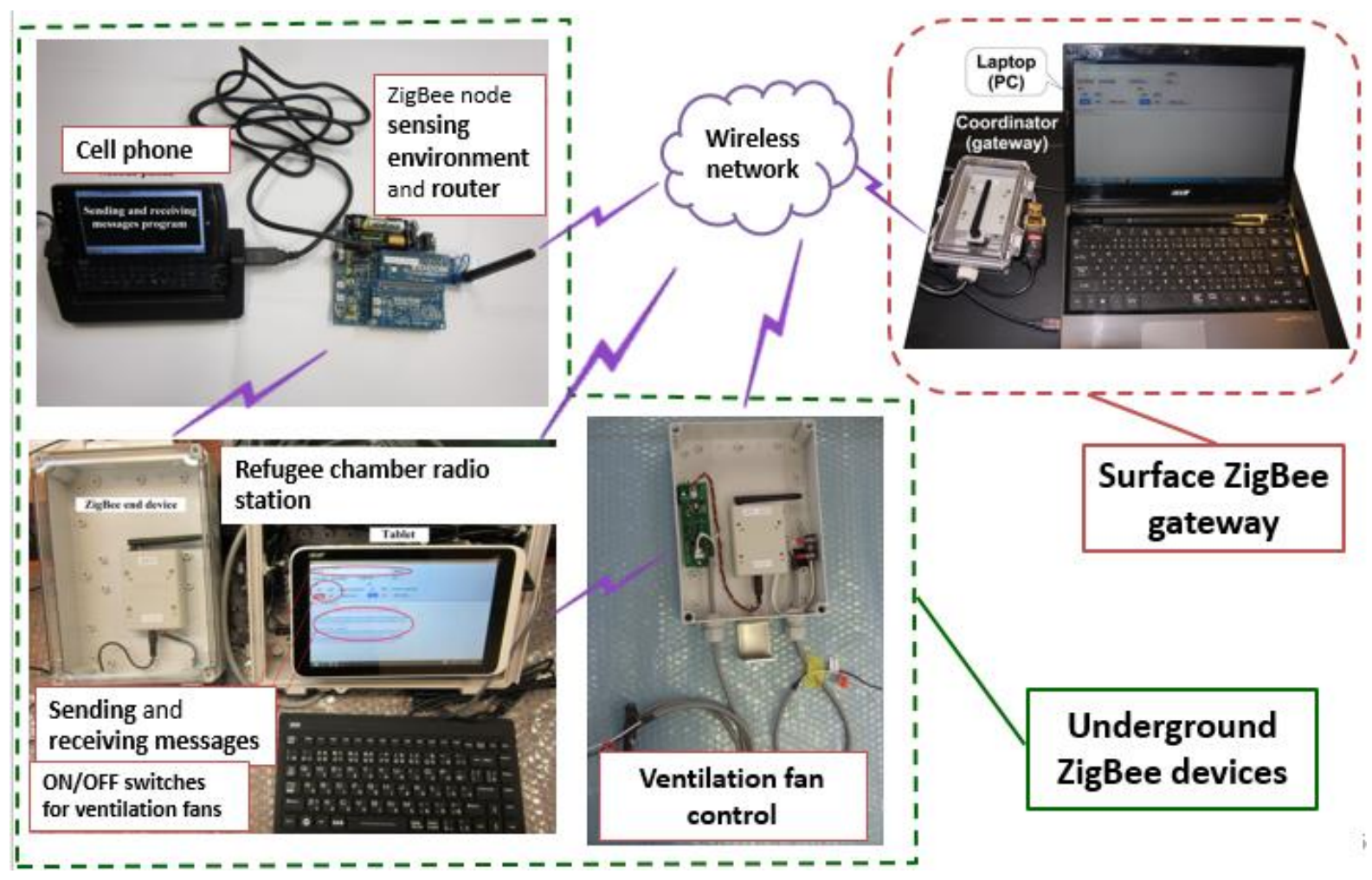

Figure 16. Applicable ZigBee nodes for underground environments

Ventilation fan control is also provided by the ZigBee node with its ability to wirelessly connect to the fans. A screenshot of the designed program showing on PCs (laptop and tablet) with ON/OFF switches and receiving/sending messages is illustrated in Figure 18. There are separate command icons for each auxiliary fan in the program. Routers are manufactured with the ability of real-time sensing of the environment as well as relaying communication signals throughout the network. A digital temperature, humidity and luminance compound sensor on board of each JN5148, with advanced sensitivity and continued stability, were utilised for the experiment. ZigBee nodes were placed in the boxes to minimise adverse environmental effects on their operation.

Alternating current $(\mathrm{AC})$ power was required for the ZigBee coordinator and radio station (end-device). Therefore, the test line to establish the ZigBee network selected was based on the availability of power points on level 11 . Routers were used which were compatible with 
direct current (DC) power between 9 and 32 volts. In this experiment, a 12-volt battery was used with $3 \mathrm{dBm}$ transmitting power.

To set up the experiment, the coordinator was first turned on and connected to the laptop to save and monitor data and also to establish an automatic wireless network to join routers and end devices to the network. The applicable ZigBee nodes were arranged at level 11 based on the classification of results in table 2 in order to verify the system design. This is illustrated in Figure 17. Also, the coordinator was located in refugee chamber connecting to the power point which was supplied with 220 volts. The first router's preferred location is in a line of sight from the coordinator at the specified maximum distance otherwise, an imbalance in the number of nodes in the system design will negatively affect network performance.

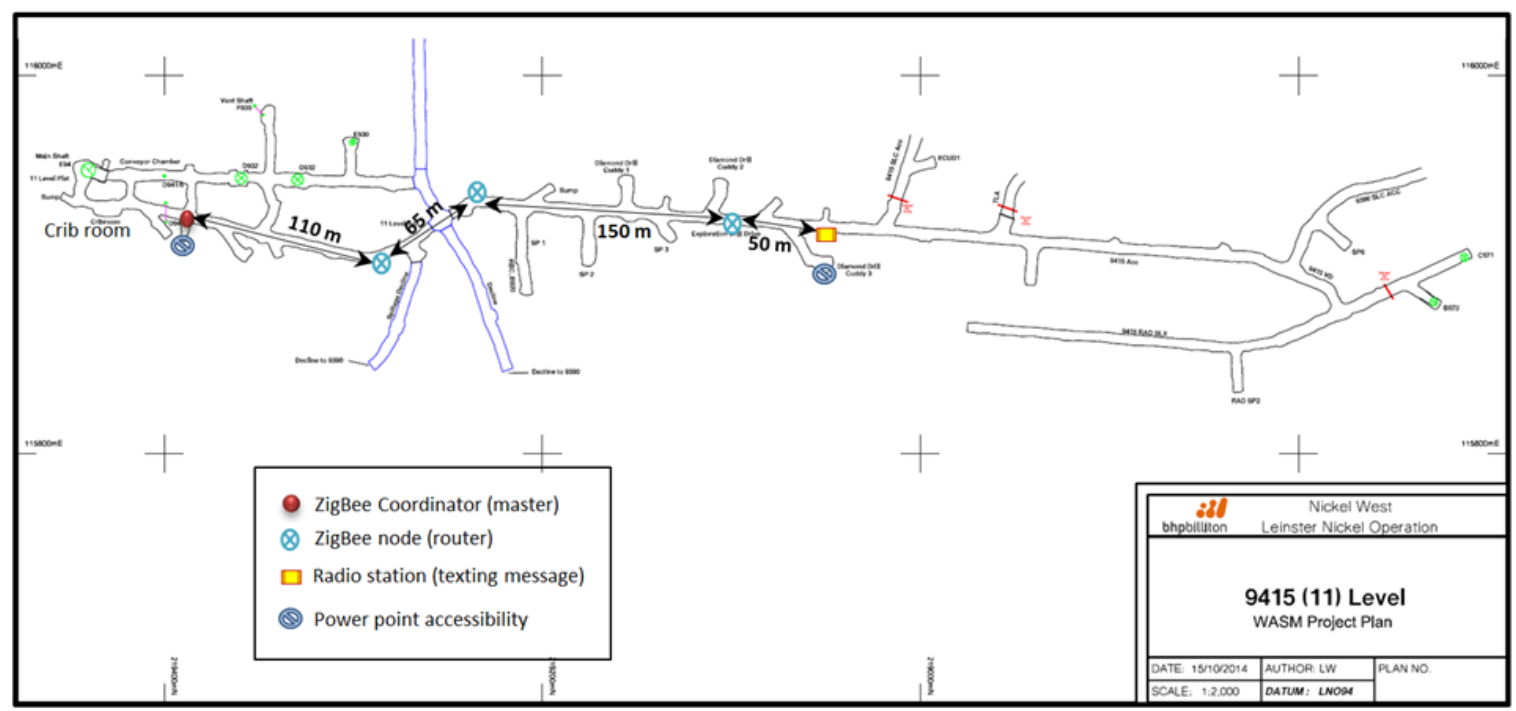

Figure 17. Arrangement of ZigBee nodes for the verification of the system design

For example, if a ZigBee network with a high density of nodes is used, the ability to control traffic congestion will be affected as well as impacting overall economic costs. On the other hand, if there are fewer nodes over a greater communication distance, the reliability of communication would be the principal concern for network performance. As a result, an 
accurate appraisal of optimally arranged nodes for the ZigBee network, as was done during the system design experiment, must include consideration of controllable and uncontrollable parameters. The ZigBee network was constructed in accordance with the outcomes that appraise the total length of the ZigBee network over $365 \mathrm{~m}$ that had a total of 5 nodes through level 11, as shown in Figure 17.

\subsection{Experiment results}

The radio station was mounted at the end of the test line to communicate with the coordinator through the other nodes. Successful communication between coordinator and radio station is illustrated in Figure 18 where the messages sent (as red) and received (as blue) were transmitted from the coordinator to the radio station. As shown in Figure 18, the ControlTerm program was configured both on the laptop which was connected to the coordinator as well as the tablet connected to the radio station.

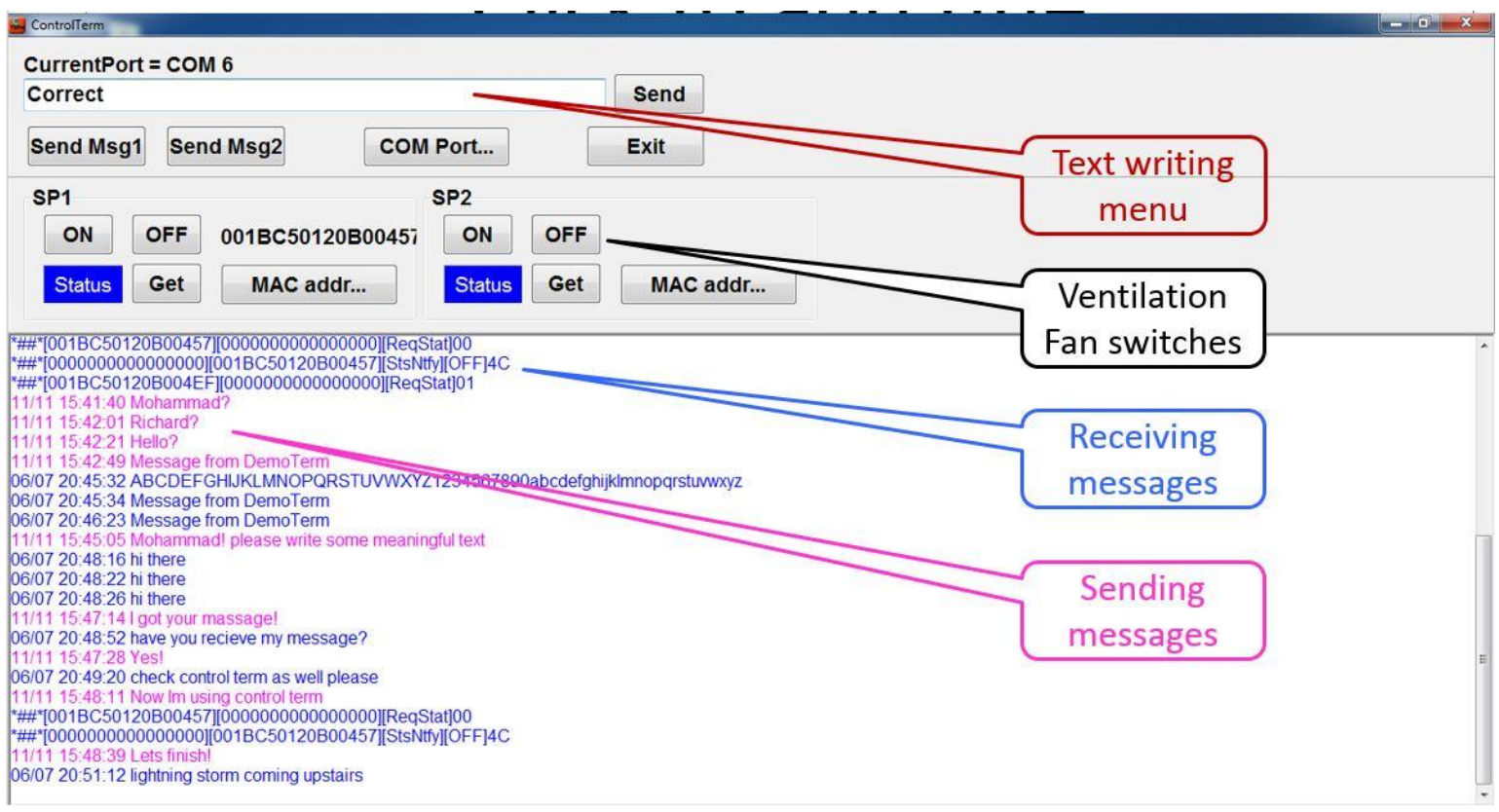

Figure 18. ControlTerm program to send (red) and receive (blue) messages from the coordinator to the radio station 
In summary, these experiments demonstrated that wireless sensor networks can significantly improve the efficiency of underground monitoring regarding personnel, plant, and equipment location, operational readings, and communications. They also verified that ZigBee network performance of a carefully designed system is reliable for underground wireless monitoring and communication systems. The results show that stable communication distances for ZigBee nodes are sustainable up to $360 \mathrm{~m}$ and up to $120 \mathrm{~m}$ in straight and curved tunnels, respectively. Additionally, the following outcomes were successfully achieved: the real-time monitoring of underground spaces in terms of temperature, humidity and illumination and the control of ventilation system by a master node (coordinator) as well as communication between nodes.

\section{Conclusions}

This paper indicates the improvement of mine automation for a safe workplace utilising WSNs. It suggests developing a methodology to establish a reliable ZigBee network for monitoring and communication in an underground mine. The challenge of integrating executable and analytic models performed within the underground mine in Western Australia was addressed. The implementation of the ZigBee network is initially organised based on the system design specifications. These specifications themselves are determined from an investigation of reliable and maximum communication distances under different conditions. Specifications cannot be determined unless the effects of all controllable and uncontrollable parameters are appraised and assessed at maximum distances. The model was verified by running experiments for temperature, humidity and illumination readings, texting message, and controlling ventilation fan through the underground mine. Since every underground mine site has varying controllable and uncontrollable parameters, experiments have to be individually designed when developing a functional model. Technical and economic evaluations can also be undertaken using this experimental model. 


\section{References:}

Ben Maissa, Y., Kordon, F., Mouline, S., \& Thierry-Mieg, Y. (2013). Modeling and Analyzing Wireless Sensor Networks with VeriSensor: An Integrated Workflow. In M. Koutny, W. M. P. Aalst \& A. Yakovlev (Eds.), Transactions on Petri Nets and Other Models of Concurrency VIII (pp. 24-47). Berlin, Heidelberg: Springer Berlin Heidelberg. http://dx.doi.org/:10.1007/978-3-64240465-8 2

Benkic, K., Malajner, M., Planinsic, P., \& Cucej, Z. (2008). Using RSSI value for distance estimation in wireless sensor networks based on ZigBee. 15th International Conference on Systems, Signals and Image Processing. Slovenia. Doi.10.1109/IWSSIP.2008.4604427. http://ieeexplore.ieee.org/document/4604427/

Ha, Y.-g., Eun, A.-c., \& Byun, Y.-c. (2013). Efficient Sensor Localization for Indoor Environments Using Classification of Link Quality Patterns. International Journal of Distributed Sensor Networks, 2013, 6. http://dx.doi.org/10.1155/2013/701259

Moridi, M. A., Kawamura, Y., Sharifzadeh, M., Chanda, E. K., \& Jang, H. (2014). An investigation of underground monitoring and communication system based on radio waves attenuation using ZigBee. Tunnelling and Underground Space Technology, 43(0), 362-369. http://dx.doi.org/http://dx.doi.org/10.1016/j.tust.2014.05.011

Moridi, M. A., Kawamura, Y., Sharifzadeh, M., Chanda, E. K., Wagner, M., \& Okawa, H. (2018). Performance analysis of ZigBee network topologies for underground space monitoring and communication systems. Tunnelling and Underground Space Technology, 71(0), 201-209. http://www.sciencedirect.com/science/article/pii/S0886779815301115?via\%3Dihub

Robinson, K. (2012). System Modelling \& Design Using Event-B. School of Computer Science and Engineering: The University of New South Wales.

Stanley-Marbell, P., Basten, T., Rousselot, J., Oliver, R. S., Karl, H., Geilen, M., . . . Decotignie, J.-D. (2008). System models in wireless sensor networks (ESR-2008-06 ). Department of Electrical Engineering Electronic Systems:

Zarei, H., Uromeihy, A., \& Sharifzadeh, M. (2013). A new tunnel inflow classification (TIC) system through sedimentary rock masses. Tunnelling and Underground Space Technology, 34, 1-12. 